\title{
New insight into butyrate metabolism
}

\author{
Knud Erik Bach Knudsen ${ }^{1 *}$, Anja Serena ${ }^{1}$, Nuria Canibe ${ }^{1}$ and Katri S. Juntunen ${ }^{2}$ \\ ${ }^{I}$ Danish Institute of Agricultural Sciences, Department of Animal Nutrition and Physiology, \\ P.O. Box 50, DK-8830 Tjele, Denmark \\ ${ }^{2}$ University of Kuopio, Department of Clinical Nutrition, P.O. Box 1627, FIN-70211 Kuopio, Finland
}

\begin{abstract}
Butyrate is a $\mathrm{C}_{4}$ acid produced by microbial fermentation of carbohydrates and protein in the large intestine of all animal species. The factor of prime importance for the production rate of butyrate in the lower gut is type and levels of non-digestible carbohydrates entering the large intestine. It was previously believed that $85-90 \%$ of the butyrate produced in the gut was cleared when passing the gut epithelium, but recent studies with catheterised pigs have shown that the concentration of butyrate in the portal vein is strongly influenced by the production rate in the large intestine. Increased gut production of butyrate further raises the circulating level of butyrate. For good reason it is not possible with current technologies to perform direct measurements of the variation in the butyrate concentration in the portal vein of human subjects, but short-chain fatty acid levels in portal blood from sudden-death victims, subjects undergoing emergency surgery or planned surgery have indicated a higher gut production and absolute and relative concentration of butyrate in non-fasted as compared with fasted human subjects. However, despite an expected higher gut production of butyrate when feeding a high-fibre rye-bread-based diet as compared with a low-fibre wheat-bread-based diet, there was no difference in absolute or relative levels of butyrate in the peripheral blood of human subjects.
\end{abstract}

\section{Butyrate: Catheterised pigs: Metabolism}

Butyrate is a $\mathrm{C}_{4}$ acid produced along with other short-chain fatty acids (SCFA) by microbial fermentation of dietary and endogenous residues in the lower gut of all animal species. The predominant substrates for the microbial fermentation are the residues not digested by endogenous enzymes in the small intestine, the main residues being non-digestible oligosaccharides, resistant starch and NSP (Cummings \& Englyst, 1987, 1995). The butyrate produced is rapidly taken up from the gut lumen and is the principal oxidative fuel for the colonocytes, where it is metabolised by $\beta$-oxidation (Roediger, 1980). In addition to being an important respiratory fuel, butyrate has also been shown to have several cellular effects, i.e. to have an influence on cell maturation, cell differentiation and apoptosis, presumably mediated by the effect butyrate may have on gene and protein expressions (Smith et al. 1998). Disease stages of the colon have also been linked to an impaired butyrate metabolism of the colonocytes (Roediger, 1980; Kim et al. 1981). The discovery of the metabolic importance of butyrate has thus enabled us to put earlier epidemiological observations into a molecular perspective
(World Cancer Research Fund/American Institute of Cancer Research, 1997).

Until recently, much emphasis on health implications of butyrate has been related to the colon. However, since the cellular effects of butyrate, at least regarding histone acetylation, appear to be universal in mammalian cells (Smith et al. 1998), the question is to what extent butyrate has to be produced in the gut, so that it can raise the circulating levels of butyrate. This question has further been accentuated by recent findings showing that butyrate regulates the expression of insulin-like growth factor-binding protein in the human mammary and prostate cells (Tsubaki et al. 2001, 2002), which, to have any biological meaning, requires a raised level of butyrate in the bloodstream some distance from the gut. The main purpose of the present paper is to discuss current knowledge concerning formation and metabolism of butyrate in single-stomached species. The paper is based on literature values and data obtained from the authors' work with catheterised pigs and analysis of blood samples from healthy human subjects fed wheat and rye diets (Juntunen et al. 2000). 


\section{Factors influencing butyrate production in the gut}

The most important determinants of fermentation in the large intestine of all single-stomached species are the amount and type of residues that enter the lower gut. The main substrates available for fermentation are NSP, various forms of resistant starch and non-digestible oligosaccharides, sugar alcohols and proteins. Hostproduced substances such as glycoproteins, exfoliated epithelial cells and pancreatic secretions are also important (Cummings \& Englyst, 1987, 1995). The non-digested carbohydrates are exposed to the action of the hydrolytic bacteria, which produce extracellular cellulases and other enzymes that degrade the polysaccharides to oligosaccharides. The oligosaccharides produced are either used directly by the hydrolytic bacteria or cross-fed to the nonhydrolytic bacteria that convert the carbohydrate monomers (pentoses and hexoses), through a variety of intermediates, mainly to acetate, propionate and butyrate.

The carbohydrates present in the diet will, due to variations in chemical composition and physico-chemical properties, to a large extent influence not only the amount but also the proportion of the acids produced during fermentation. This outcome is shown in Table 1 in which results from in vitro fermentation studies using pure polysaccharides, fibre fractions and ileal effluents from human subjects and pigs are summarised (Englyst et al. 1987; Bourquin et al. 1993; Casterline et al. 1997; Christensen et al. 1999; Glitsø et al. 2000). The results indicate a wide variation in the yield of SCFA and their proportions. Polysaccharides and fractions that stimulate the formation of butyrate are starch and brans from wheat and oats, while xylan, pectin and pectin-rich fractions (apple) are all associated with a relatively low formation of butyrate.

\section{Absorption and metabolism of butyrate}

The concentration of SCFA in the large intestine is remarkably similar across a variety of animal species and usually only marginally influenced by dietary factors (Breves \& Stuck, 1995). The rate of absorption is consequently under normal physiological conditions in balance with the lumen production rate. Estimates of SCFA absorption rates of isolated sections of gut epithelium also show a high extent of similarity among the different animal species: $8-10 \mu \mathrm{mol} / \mathrm{cm}^{2}$ per $\mathrm{h}$ for pigs, and $6-12 \mu \mathrm{mol} / \mathrm{cm}^{2}$ per h for man (Argenzio \& Southworth, 1975; McNeil et al. 1978). The SCFA are metabolised to varying extents during the absorption process and previously published results from isotope studies in ruminants have led to the conclusion that a substantial proportion of all the SCFA produced was metabolised by the gut epithelium (Bergman \& Wolff, 1971; Bergman, 1990). In the case of butyrate, $85-90 \%$ of that produced in the large bowel was assumed to be metabolised in the intestinal wall (Bergman \& Wolff, 1971; Bergman, 1990). Recent studies with ruminants, however, have introduced some uncertainty about this high epithelial utilisation of acetate and propionate particularly, while they still point to butyrate utilisation of approximately $60 \%$ in the rumen epithelium (Kristensen et al. 2000; Kristensen \& Danfær, 2001).

No specific data from isotope studies are available for single-stomached species, but it has been assumed that the colonic epithelium, as in ruminants, utilises a high proportion of the butyrate, leaving only a small proportion of that produced in the gut to be recovered in the portal vein (Bergman, 1990). However, recent studies with catheterised pigs (Fig. 1) fed either on barley flour or rye bread indicate a substantial transfer of butyrate from the gut to the portal vein

Table 1. Short-chain fatty acid (SCFA) production during in vitro fermentation of pure polysaccharides, fibre fractions and ileal effluents from human subjects and pigs

\begin{tabular}{|c|c|c|c|c|c|}
\hline \multirow[b]{2}{*}{ Substrate } & \multicolumn{3}{|c|}{ Proportion } & \multirow[b]{2}{*}{$\mathrm{SCFA}^{*}(\mathrm{mmol} / \mathrm{g})$} & \multirow[b]{2}{*}{ Reference } \\
\hline & $A$ & $\mathrm{P}$ & $\mathrm{B}$ & & \\
\hline \multicolumn{6}{|l|}{ Polysaccharides } \\
\hline Starch & 50 & 22 & 29 & $8 \cdot 70$ & Englyst et al. (1987) \\
\hline Xylan & 82 & 15 & 3 & 8.57 & \\
\hline Pectin & 84 & 14 & 2 & $5 \cdot 41$ & \\
\hline Carboxymethylcellulose & 66 & 20 & 12 & 0.41 & Bourquin et al. (1993) \\
\hline \multicolumn{6}{|l|}{ Dietary fibre fractions } \\
\hline Williamson oat fibre (hulls) & 62 & 17 & 21 & $0 \cdot 42$ & \\
\hline Oat bran & 50 & 37 & 14 & $2 \cdot 66$ & Casterline et al. (1997) \\
\hline Wheat bran & 57 & 33 & 12 & 1.09 & \\
\hline Apple & 68 & 21 & 6 & 1.56 & \\
\hline \multicolumn{6}{|l|}{ Ileal effluents: human subjects } \\
\hline Control diet & 72 & 16 & 12 & $4 \cdot 82$ & Silvester et al. (1995) \\
\hline High-resistant starch diet & 66 & 17 & 17 & $4 \cdot 94$ & \\
\hline Low-fibre wheat & 54 & 27 & 10 & $3 \cdot 39$ & Christensen et al. (1999) \\
\hline High-fibre wheat bran & 57 & 24 & 12 & $2 \cdot 85$ & \\
\hline High-fibre oat bran & 49 & 26 & 15 & $3 \cdot 91$ & \\
\hline Whole rye & 40 & 41 & 17 & $4 \cdot 80$ & Glitsø et al. (2000) \\
\hline
\end{tabular}

A, acetate; $P$, propionate; $B$, butyrate

*SCFA produced expressed as $\mathrm{mmol} / \mathrm{g}$ polysaccharides in dietary fibre residue or ileal effluents. 


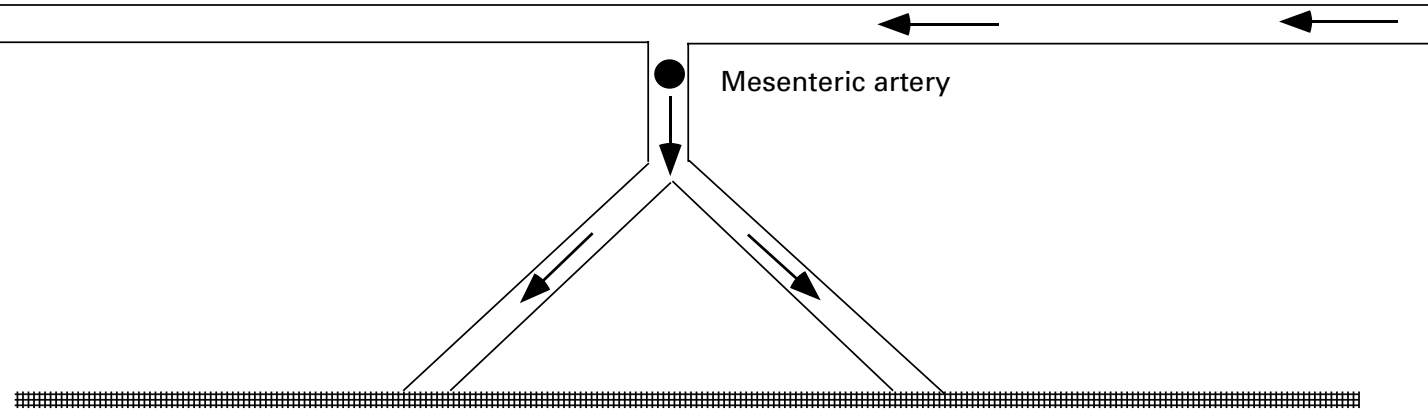

Gastrointestinal tract

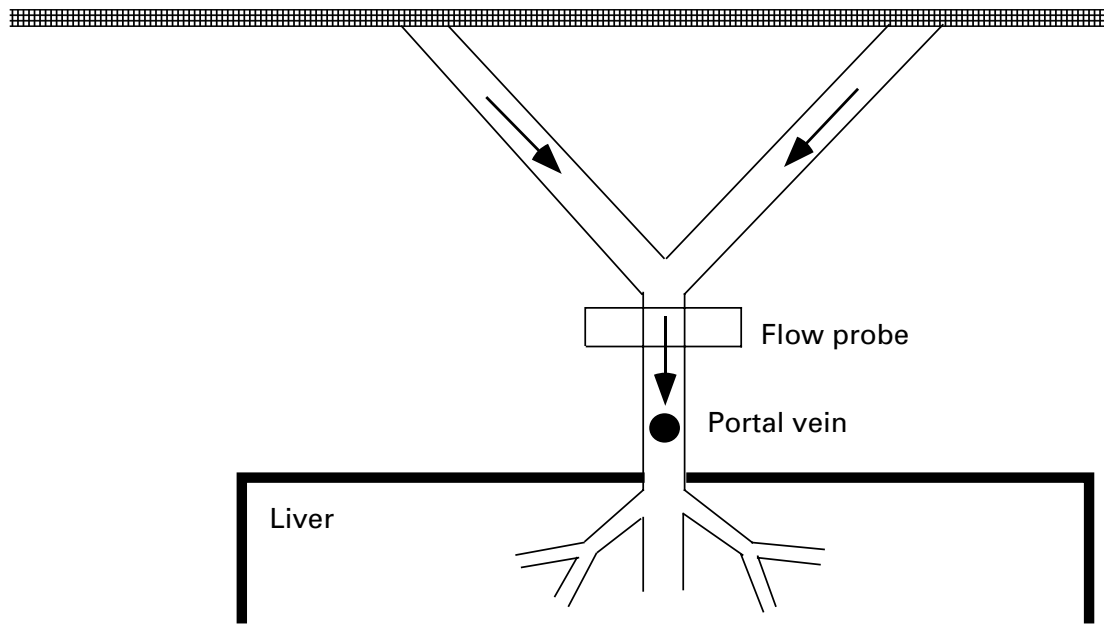

Fig. 1. Catheterised pig model with permanent catheters placed in the portal vein and mesenteric artery and with an ultrasonic flow probe attached to the portal vein to monitor the blood flow. For details of experimental protocol, see Bach Knudsen et al. (2000).
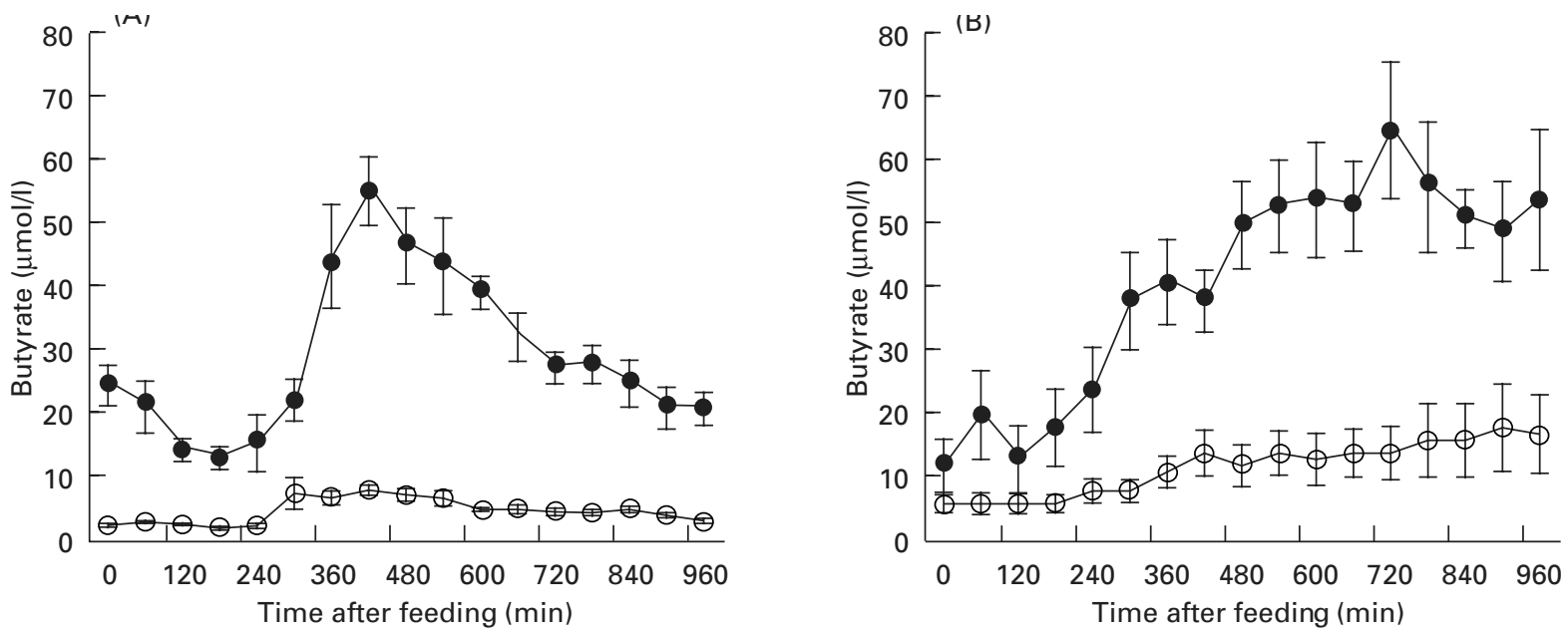

Fig. 2. Concentrations of butyrate in the portal vein $(\bullet)$ and mesenteric artery $(O)$ after feeding $45 \mathrm{~g}$ NSP from barley flour $(\mathrm{A})$ or $116 \mathrm{~g}$ NSP from rye bread (B). The values are averages with their standard errors represented by vertical bars for five pigs for barley flour and four pigs for rye bread. On the day before blood sampling, the pigs were fed a semi-synthetic diet containing no fibre components. The animals were fasted for $16 \mathrm{~h}$, then fed a pulse dose of the barley flour or the rye bread and the blood was sampled hourly for a total period of $16 \mathrm{~h}$. The relative proportions of cellulose- $\beta$-glucan-arabinoxylans were 18:33:40 for barley flour and 10:10:63 for rye bread and the proportion of soluble NSP in barley flour was 0.46 and in rye bread 0.27.

(Fig. 2 (A) and (B)). As can be seen from Fig. 2 (A), with barley flour the portal level of butyrate was low (about $20 \mu \mathrm{mol} / \mathrm{l}$ ) and almost constant up to $300 \mathrm{~min}$ after feeding, followed by a rapid rise over the next $2 \mathrm{~h}$ to a level of $60 \mu \mathrm{mol} / 1$ and then a constant decline over the following period, approaching the prefeeding level after $16 \mathrm{~h}$. With the 
rye bread, the portal level of butyrate was also constant between 0 and $300 \mathrm{~min}$ after feeding, but after $300 \mathrm{~min}$ the concentration of butyrate increased gradually to a plateau level at $480 \mathrm{~min}$ after feeding. It should also be noted that while the variation in the level of butyrate in the mesenteric artery was minimal with the barley-flour diet, the level of butyrate in the study with rye bread increased from about $5 \mu \mathrm{mol} / 1$ between 0 and $300 \mathrm{~min}$ after feeding to $15-20 \mu \mathrm{mol} / \mathrm{l}$ when butyrate reached the plateau level. Thus, under conditions of active fermentation the production of butyrate in the large intestine clearly exceeds the clearance rate of the epithelial cells, resulting in an increased level of butyrate in the portal vein and, with the rye bread, in the mesenteric artery.

The data in Fig. 2 are further substantiated by data for the quantitative uptake of SCFA from catheterised pigs that had been fed the same diet for a longer period of time (GiusiPeerier et al. 1989; Van der Meulen et al. 1997; Bach Knudsen et al. 2000; A Serena, ABK Kjær, H Jørgensen, R Engberg and KE Bach Knudsen, unpublished results). The total production of butyrate was low in the low-fibre diets (low-fibre cellulose $(60 \mathrm{~g} / \mathrm{kg})$, low-fibre wheat and maize). In the diets where cellulose was used to raise the dietary fibre level (high-fibre cellulose $(160 \mathrm{~g} / \mathrm{kg})$ and wheat bread prepared from wheat flour with added cellulose) the production of butyrate increased but the percentage of butyrate in the absorbed SCFA remained relatively low at about 5-6. In contrast to these findings there was a substantial rise in the total production of butyrate as well as in the relative proportion of butyrate when the amount of carbohydrates potentially available for fermentation was increased by brans from either wheat or oats, rye fibre or potato starch. Thus, from Table 2 it can be concluded that there will be a substantial change in the amount of butyrate passing from the gut and to the bloodstream in response to the type and levels of dietary residues that enter the large intestine.

Direct quantification of the SCFA production in human subjects is not possible because of the difficulties in accessing the large intestine and the portal vein. However, an estimate of the uptake of SCFA in human subjects can be obtained by measuring the static arterial-venous differences of portal and arterial blood from individuals who had died suddenly (road accidents, other violent deaths, CHD) or from patients undergoing emergency or planned surgery (Dankert et al. 1981; Cummings et al. 1987, 1989; Peters et al. 1992). For sudden-death victims and patients undergoing emergency surgery it can be assumed that they have been eating their habitual diet (presumably low in fibre), whereas blood samples from the subjects undergoing planned surgery are taken in the fasted state. The time interval between the last meal and when the blood sample was taken would have a major influence on the estimated production of all SCFA, and butyrate in particular, as indicated by the data in Table 2. The production of total SCFA and butyrate and the concentration of butyrate (data not shown) were markedly higher in the non-fasted stage as compared with the fasted stage, reflecting the higher net supply of SCFA from the gut. It should also be noted that the estimated production of total SCFA and butyrate in the fed state approaches the level found in pigs fed the low-fibre wheat or maize diets.

Table 2. Production of short-chain fatty acids (SCFA) as estimated in vivo in conscious catheterised pigs fed diets with variable amounts of non-digestible carbohydrates and in non-fasted and fasted human subjects that had either died suddenly or undergone emergency or planned surgery

\begin{tabular}{|c|c|c|c|c|c|c|}
\hline \multirow[b]{2}{*}{ Experimental conditions } & \multicolumn{4}{|c|}{ Production (mmol/d) } & \multirow[b]{2}{*}{ B (\% total SCFA) } & \multirow[b]{2}{*}{ Reference } \\
\hline & SCFA & A & $P$ & B & & \\
\hline \multicolumn{7}{|l|}{ Catheterised pigs* } \\
\hline Low-fibre cellulose (6 \%) & 1184 & 899 & 213 & 45 & $3 \cdot 8$ & Giusi-Peerier et al. (1989) \\
\hline High-fibre cellulose (16 \%) & 1428 & 987 & 324 & 84 & $5 \cdot 9$ & \\
\hline Low-fibre wheat & 720 & 317 & 347 & 46 & $6 \cdot 4$ & Bach Knudsen et al. (2000) \\
\hline High-fibre wheat bran & 738 & 320 & 335 & 77 & $10 \cdot 4$ & \\
\hline Wheat bread & 1563 & 897 & 558 & 91 & $5 \cdot 8$ & $\begin{array}{l}\text { A Serena, ABK Kjær, H Jørgensen, } \\
\text { R Engberg and KE Bach Knud- } \\
\text { sen (unpublished results) }\end{array}$ \\
\hline Rye bread & 2064 & 1005 & 771 & 273 & $13 \cdot 2$ & \\
\hline Maize & 480 & 275 & 142 & 31 & $6 \cdot 5$ & Van der Meulen et al. (1997) \\
\hline Maize and potato & 1446 & 760 & 210 & 380 & $26 \cdot 3$ & \\
\hline Potato & 2134 & 1162 & 267 & 570 & $26 \cdot 7$ & \\
\hline \multicolumn{7}{|l|}{ Human subjects $†$} \\
\hline Autopsy (UK, non-fasted) & 425 & 270 & 119 & 36 & $8 \cdot 5$ & Cummings et al. (1987) \\
\hline $\begin{array}{l}\text { Surgical (South Africa, non- } \\
\text { fasted) }\end{array}$ & 377 & 197 & 115 & 65 & $17 \cdot 2$ & Cummings et al. (1989) \\
\hline Surgical (The Netherlands, fasted) & 168 & 114 & 43 & 11 & $6 \cdot 6$ & Dankert et al. (1981) \\
\hline Surgical (New Zealand, fasted) & 157 & 88 & 43 & 26 & $8 \cdot 3$ & Peters et al. (1992) \\
\hline
\end{tabular}

A, acetate; $P$, propionate; $B$, butyrate.

* The production of SCFA in pigs was calculated as arterial-venous concentration difference $\times$ blood flow obtained from flow measurements using a flow probe (Giusi-Peerier et al. 1989; Bach Knudsen et al. 2000; A Serena, ABk Kjær, H Jørgensen, R Engberg and KE Bach Knudsen (unpublished results) or p-aminohippuric acid (Van der Meulen et al. 1997).

$\dagger$ The production of SCFA in human subjects was estimated as arterial-venous concentration difference $\times 1440$ (assuming a blood flow of $1 \mathrm{l} / \mathrm{min}$ ). 


\section{Butyrate in the peripheral blood}

The concentration of butyrate in the blood that flows from the intestinal tract to the liver, the heart and the lungs in both pigs and man will to a great extent mimic the fluctuation in gut production rates. For instance, the concentration of butyrate in portal blood of pigs fed a maize diet was only $20 \mu \mathrm{mol} / 1$, but reached $360 \mu \mathrm{mol} / 1$ with a potato diet (Van der Meulen et al. 1997). In the artery the variation in butyrate was less marked; $10 \mu \mathrm{mol} / 1$ with the maize diet and $60 \mu \mathrm{mol} / 1$ with the potato diet (Van der Meulen et al. 1997). However, will this fluctuation in gut production rate be translated into concentration differences in the general circulation? To investigate this aspect, a crossover study was performed using a semi-synthetic diet containing $80 \mathrm{~g}$ cellulose $/ \mathrm{kg}$, or wheat- or rye-bread diets similar in composition to those used in the experiment with catheterised pigs (A Serena, ABK Kjær, H Jørgensen, R Engberg and KE Bach Knudsen, unpublished results). In this study blood samples were taken from the jugular vein at the end of each balance period. The butyrate production with the semisynthetic diet has not been determined in catheterised pigs, but it would probably be of the order of $40-50 \mathrm{mmol} / \mathrm{d}$ (similar to low-fibre wheat; Table 2), while the butyrate production for the wheat and rye breads is about 110 and $330 \mathrm{mmol} / \mathrm{d}$ respectively (A Serena, ABK Kjær, H Jørgensen, R Engberg and KE Bach Knudsen, unpublished results), taking into account the differences in feeding level between the two experiments. Table 3 shows that total SCFA in the jugular vein was significantly lower $(P<0 \cdot 05)$ when feeding the semi-synthetic diet as compared with the wheat and rye diets. For butyrate, the absolute and relative proportion was even higher, with six-fold and four-fold increases in concentration and relative proportion respectively for the rye diet when compared with the semisynthetic diet. From studies with pigs it is thus clear that the concentration of butyrate in the peripheral blood will be influenced by the gut production rate of butyrate. For healthy human subjects, however, it has not been possible to provide evidence for the same fluctuation in butyrate

Table 3. Short-chain fatty acids (SCFA) and butyrate in the jugular vein blood from pigs and venous blood of human subjects consuming a semi-synthetic diet and diets based on wheat or rye breads

\begin{tabular}{lccc}
\hline & & \multicolumn{2}{c}{ Butyrate } \\
\cline { 3 - 4 } Diet & SCFA $(\mu \mathrm{mol} / \mathrm{l})$ & $\mu \mathrm{mol} / \mathrm{l}$ & $\%$ total SCFA \\
\hline Pigs* $^{*}$ & & & \\
Semi-synthetic diet & $136^{\mathrm{a}}$ & $1 \cdot 2^{\mathrm{a}}$ & $0 \cdot 9^{\mathrm{a}}$ \\
Wheat bread & $178^{\mathrm{b}}$ & $3 \cdot 7^{\mathrm{b}}$ & $2 \cdot 0^{\mathrm{b}}$ \\
Rye bread & $191^{\mathrm{b}}$ & $7 \cdot 3^{\mathrm{c}}$ & $3 \cdot 8^{\mathrm{c}}$ \\
Healthy human subjects $\dagger$ & & & \\
Wheat bread & 162 & $1 \cdot 6$ & $1 \cdot 1$ \\
Rye bread & 164 & $1 \cdot 7$ & $1 \cdot 1$ \\
\hline
\end{tabular}

a,b,c Values for SCFA and butyrate in pigs with unlike superscript letters were significantly different $(P<0.05)$

${ }^{*}$ Average values for six pigs.

†Average values for seventeen men and twenty-one women in the wheat and the rye group. The women consumed the diets in amounts that provided $12.0 \mathrm{~g}$ dietary fibre from wheat/d and $26.1 \mathrm{~g}$ dietary fibre from rye/d and the men $14.7 \mathrm{~g}$ dietary fibre from wheat/d and $31.4 \mathrm{~g}$ dietary fibre from rye/d (Juntunen et al. 2000). concentration in the peripheral blood (Table 3). Fasted venous blood samples from Finnish women and men (Juntunen et al. 2000) fed either a low-fibre wheat diet or a high-fibre rye diet were analysed. Based on the results of the pig studies these two types of diets would be expected to show differences in the production rate of butyrate in the large intestine. However, as indicated by the data in Table 3, there was no difference in either concentration or relative proportion of butyrate in the venous blood from subjects on the wheat and the rye diets. Similar results have been obtained when analysing blood samples from patients with prostate-related conditions who consumed two high-fibre wheat or rye diets (KE Bach Knudsen, unpublished results).

Why this apparent species difference? The most probable reason is the difference in the level of fermentable carbohydrate intake. All measurements show that the intake of fermentable carbohydrates is much higher in pigs than in human subjects, and since the tissue utilisation of butyrate cannot be expected to be different (Bergman, 1990), it is quite likely that the gut production of butyrate in human subjects never reaches a level that is sufficient for raising the systemic level of butyrate. However, it cannot be completely excluded that the peripheral levels of butyrate, even in human subjects, can be raised when diets that are more butyrogenic than rye bread, i.e. diets containing high levels of resistant starch, are consumed.

\section{The concentration issue}

The studies with pigs clearly indicate that increased gut production of butyrate will translate into a rise in the concentration of butyrate in the bloodstream. There is probably a similar relationship in man, although the magnitude is lower. However, for both species the fluctuation in butyrate in the peripheral blood is relatively low. The question remains, therefore, as to whether the concentration of butyrate will reach sufficient levels for the molecule to have any nutritional relevance for cells not in direct connection with the gut. For instance, with the prostate cancer and normal mammary cell lines studied by Tsubaki et al. (2001) and Tsubaki et al. (2002), the concentration of butyrate required to manipulate the cell lines has typically been in the range $0-10 \mathrm{mmol} / \mathrm{l}$; a level that is only reached in the lumen of the large intestine (typical values about $20 \mathrm{mmol} / \mathrm{l}$ ). However, levels similar to those of the lumen will never be reached in any mammalian cell, since the butyrate concentration is most probably similar to that found in the blood.

\section{Conclusions}

Results from pigs show that the concentration of butyrate in the blood passing from the intestinal tract to the liver, the heart and the lungs mimics the production rate in the large intestine. Increased gut production of butyrate further raises the circulating level of butyrate. Values for SCFA in portal blood from human subjects in the non-fasted state showed a higher absolute and relative concentration of butyrate and a higher production of SCFA and of butyrate as compared with fasted subjects. There was, however, no difference in absolute or relative levels of butyrate in venous blood of 
human subjects consuming wheat or rye breads with contrasting levels of dietary fibre.

\section{Acknowledgements}

The preparation of the paper was possible thanks to the financial support provided by The Danish Agricultural and Veterinary Research Council to K.E.B.K.

\section{References}

Argenzio RA \& Southworth M (1975) Sites of organic acid production and absorption in the gastrointestinal tract of the pig. American Journal of Physiology 228, 454-464.

Bach Knudsen KE, Canibe N \& Jørgensen H (2000) Quantification of the absorption of nutrients deriving from carbohydrate assimilation: Model experiment with catheterised pigs fed on wheat and oat based rolls. British Journal of Nutrition 84, 449-458.

Bergman EN (1990) Energy contributions of volatile fatty acids from the gastrointestinal tract in various species. Physiological Reviews 70, 567-590.

Bergman EN \& Wolff JE (1971) Metabolism of volatile fatty acids by liver and portal-drained viscera in sheep. American Journal of Physiology 221, 586-592.

Bourquin LD, Titgemeyer EC, Fahey GC Jr \& Garleb KA (1993) Fermentation of dietary fibre by human colonic bacteria: disappearance of short-chain fatty acid production from, and potential water-holding capacity of, various substrates. Scandinavian Journal of Gastroenterology 28, 249-255.

Breves G \& Stuck K (1995) Short-chain fatty acids in the hindgut. In Physiological and Clinical Aspects of Short-Chain Fatty Acids, pp. 73-85 [JH Cummings, JL Rombeau and T Sakata, editors]. Cambridge: Cambridge University Press.

Casterline JL, Oles CJ \& Ku Y (1997) In vitro fermentation of various food fiber fractions. Journal of Agricultural and Food Chemistry 45, 2463-2467.

Christensen DN, Bach Knudsen KE, Wolstrup J \& Jensen BB (1999) Integration of ileum cannulated pigs and in vitro fermentation to quantify the effect of diet composition on the amount of short-chain fatty acids available from fermentation in the large intestine. Journal of Science of Food and Agriculture 79, 755-762.

Cummings JH \& Englyst HN (1987) Fermentation in the human large intestine and the available substrates. American Journal of Clinical Nutrition 45, 1243-1255.

Cummings JH \& Englyst HN (1995) Gastrointestinal effects of food carbohydrate. American Journal of Clinical Nutrition 61, 938S-945S.

Cummings JH, Gibson GR \& Macfarlane GT (1989) Quantitative estimates of fermentation in the hind gut of man. In International Symposium on Comparative Aspects of the Physiology of Digestion in Ruminant and Hindgut Fermenters, pp. 76-82 [E Skadhauge and P Nørgaard, editors]. Copenhagen, Denmark: Acta Veterinaria Scandinavica.

Cummings JH, Pomare EW, Branch WJ, Naylor CPE \& Macfarlane GT (1987) Short-chain fatty acids in human large intestine, portal, hepatic and venous blood. Gut 28, 1221-1227.

Dankert J, Zijstra JB \& Wolthers BG (1981) Volatile fatty acids in human peripheral and portal blood: quantitative determination by vacuum distillation and gas chromatography. Clinica Chimica Acta 110, 301-307.
Englyst HN, Hay S \& Macfarlane GT (1987) Polysaccharide breakdown by mixed populations of human faecal bacteria. FEMS Microbiology Ecology 95, 163-171.

Giusi-Peerier A, Fiszlewicz M \& Rérat A (1989) Influence of diet composition on intestinal volatile fatty acid and nutrient absorption in unanesthetized pigs. Journal of Animal Science 67, 386-402.

Glitsø LV, Jensen BB \& Bach Knudsen KE (2000) In vitro fermentation of rye carbohydrates including arabinoxylans of different structure. Journal of the Science of Food and Agriculture 80, 1211-1218.

Juntunen KS, Mazur WM, Liukkonen KH, Uehara M, Poutanen KS, Adlercreutz HCT \& Mykkänen HM (2000) Consumption of wholemeal rye bread increases serum concentrations and urinary excretion of enterolactone compared with consumption of white wheat bread in healthy Finnish men and women. British Journal of Nutrition 84, 839-846.

Kim YS, Tsao D, Siddiqui B, Whitehead JS, Arnstein P, Bennett J \& Hicks J (1981) Effects of sodium butyrate and dimethylsulfoxide on biochemical properties of human colon cancer cells. Cancer 45, 1185-1192.

Kristensen NB \& Danfær A (2001) The relationship between gastrointestinal production and portal absorption of short-chain fatty acids in ruminants. In Energy Metabolism in Animals, pp. 277-280 [A Chwalibog and K Jakobsen, editors]. Wageningen, The Netherlands: Wageningen Pers.

Kristensen NB, Gäbel G, Pierzynowski SG \& Danfær A (2000) Portal recovery of short-chain fatty acids infused into the temporarily-isolated and washed reticulo-rumen of sheep. British Journal of Nutrition 84, 477-482.

McNeil NI, Cummings JH \& James WPT (1978) Short chain fatty acid absorption by the human large intestine. Gut 19, 819-822.

Peters SG, Pomare EW \& Fisher CA (1992) Portal and peripheral blood short chain fatty acid concentrations after caecal lactulose installation at surgery. Gut 33, 1249-1252.

Roediger WEW (1980) The colonic epithelium in ulcerative colitis: an energy-deficiency disease? Lancet ii, 712-715.

Silvester KR, Englyst HN \& Cummings JH (1995) Ileal recovery of starch from whole diets containing resistant starch measured in vitro and fermentation of ileal effluent. American Journal of Clinical Nutrition 62, 403-411.

Smith JG, Yokoyama WH \& German JB (1998) Butyric acid from the diet: Actions at the level of gene expression. Critical Reviews in Food Science and Nutrition 38, 259-295.

Tsubaki J, Choi W-K, Ingermann AR, Twigg SM, Kim H-S, Rosenfeld RG \& Oh Y (2001) Effects of sodium butyrate on expression of members of the IGF-binding protein superfamily in human mammary epithelial cells. Journal of Endocrinology 169, 97-110.

Tsubaki J, Hwa V, Twigg SM \& Rosenfeld RG (2002) Differential activation of the IGF binding protein-3 promoter by butyrate in prostate cancer cells. Endocrinology 143, 1778-1788.

Van der Meulen J, Bakker GCM, Bakker JGM, Visser HD, Jongbloed AW \& Everts H (1997) Effect of resistant starch on net portal-drained viscera flux of glucose, volatile fatty acids, urea, and ammonia in growing pigs. Journal of Animal Science 75, 2697-2704

World Cancer Research Fund/American Institute of Cancer Research (1997) Food, Nutrition and the Prevention of Cancer: a Global Perspective. Washington, DC: World Cancer Research Fund/ American Institute of Cancer Research. 